\title{
Erratum to: Chapters 41 and 55 in \\ Design, User Experience, and Usability
}

\section{Erratum to: \\ Chapter 41 in: A. Marcus (Ed.) \\ Design, User Experience, and Usability \\ DOI: 10.1007/978-3-319-07635-5_41}

In the original version, the third author's name was misspelled. It should read as Abbas Ilyas.

\section{Erratum to:}

\section{Chapter 55 in: A. Marcus (Ed.)}

Design, User Experience, and Usability

DOI: 10.1007/978-3-319-07635-5_55

In the original version, the sixth author's name was misspelled. It should read as Abbas Ilyas. 